\title{
Educação, patrimônio cultural e relações étnico-raciais: possibilidades para a decolonização dos saberes
}

\author{
Carmem Zeli de Vargas Gil ${ }^{*}$ \\ Carla Beatriz Meinerz**
}

\begin{abstract}
Resumo
O texto articula a temática da educação das relações étnico-raciais com as abordagens das histórias e culturas indígenas, africanas e afro-brasileiras, analisando os usos de espaços de memória, monumentos, arquivos, museus e memoriais, problematizados a partir da capacidade ou não de proporcionarem visibilidade e positividade para negros e indígenas. Tem por base a perspectiva do pensamento decolonial (QUIJANO, 2005; MIGNOLO, 2003; WALSH, 2013). Aponta possibilidades de decolonização dos saberes em ações educativas vinculadas ao patrimônio cultural. Conecta-se com as experimentações de ensino, pesquisa e extensão das autoras, docentes responsáveis pela formação inicial e continuada, através do curso de História/UFRGS.
\end{abstract}

Palavras-chave: educação; patrimônio cultural; relações étnico-raciais; decolonização; saberes.

\section{Education, cultural heritage and ethnic-racial relations: possibilities for decolonisation of knowledge}

\begin{abstract}
This paper articulates the theme of education of ethnic-racial relations with the approaches of the stories and indigenous cultures, African and african-Brazilian, analyzing memory space uses, monuments, archives, museums and memorials, problematized from the ability or not to provide visibility and positive for blacks and Indians. This thematic linking is based on the perspective of decolonial thought (QUIJANO, 2005; MIGNOLO, 2003; WALSH, 2013). Indicates to decolonization possibilities of knowledge in educational activities related to cultural heritage. Connects with educational experimentation, research and extension of the authors, teachers responsible for initial and continuing education, through the course of History/UFRGS.

Keywords: education; cultural heritage; ethnic-racial relations; decolonization; knowledge.
\end{abstract}

\section{Introdução}

Começamos com uma narrativa de um episódio inusitado, efetivamente vivido e agora reinventado, porque em processo de rememoração e registro: Ao esperar na frente do portão que acessa visitações aos doentes em tratamento intensivo, no Hospital Conceição de Porto Alegre, reparo a existência de uma placa. Paro em frente ao lugar onde está o pequeno monumento e leio com atenção que se trata de uma homenagem da Associação dos Funcionários do Grupo Hospitalar ao almirante negro, líder da Revolta da Chibata, João Cândido, morto em 1969, anistiado oficialmente em 2008. Num ambiente insuspeitável, leio aquelas inesperadas palavras de reconhecimento. Com a emoção ainda em movimento dentro de mim, ouço uma jovem que dispara ao meu lado: "quer comprar uma água gelada?”; "tu já ouviu falar do João Cândido, o cara da placa?". A segunda aproximação vinha carregada de orgulho. A jovem e negra, cheia de vontade de conversar, contou-me que descobriu a

\footnotetext{
*Endereço Eletrônico: carmemz.gil@gmail.com

*** Endereço Eletrônico: carlameinerz@ gmail.com
}

história de João Cândido através daquela placa. No cotidiano de trabalho partilhado com o marido (que me abanou de longe), observou o monumento e buscou mais informações sobre o importante líder que era ali destacado. Descobriu e narrou sobre a vida de resistência e a característica de companheirismo daquele homem nascido em Encruzilhada do Sul. O repertório de informações da jovem se encontrou com o que eu sabia de meus estudos como professora de História: o almirante lutou pelos direitos dos marinheiros, foi banido em vida, homenageado após sua morte, marcado por carregar a cor do outro-subalterno numa sociedade racista e desigual. Insisto que nas palavras daquela jovem o sabor de lembrar essa história era diferente, tinha o pulsar do sentido atribuído com singular sensibilidade e a alegria da descoberta de algo pouco conhecido. Naquele momento a placa instituiu-se para mim como um lugar de memória e gerou o que chamo de encontro inusitado numa tarde ensolarada de verão ${ }^{l}$.

A partir dessa narrativa acerca de um 
monumento, criado por uma agremiação da sociedade civil organizada, em homenagem à memória de um líder trabalhador e negro, podemos indagar: o que podemos considerar sobre o patrimônio cultural a partir de uma perspectiva étnico-racial e de um pensamento pós-colonial ou descolonizador e decolonizador? Se o patrimônio cultural e seu reconhecimento oficial dependem de conflitos e negociações, é possível afirmar que a maior parte dele, em nosso país, tende a reproduzir um jeito de ver o mundo a partir do colonizador, valorizando apenas determinados grupos, etnias e suas lideranças ou heranças culturais? Uma sociedade desigual do ponto de vista étnico-racial, com histórica estigmatização de grupos não brancos, tende a esquecer e evitar o registro das memórias como a de negros e indígenas?

O episódio acima narrado nos faz pensar nos sentidos construídos pelas pessoas a partir de uma marca de memória - um prédio, uma placa, um memorial. Trata-se de marcas físicas em espaços vividos e transitados cotidianamente, sejam elas reconhecidas como patrimônio ou não. Chamamos de inusitado o encontro com aquele monumento dedicado à uma liderança negra, porque pensamos que se trata de um fenômeno relativamente recente o reconhecimento de uma pluralidade sociocultural que positive as etnias de ancestralidades não europeias e suas memórias. Identificamos como insuspeitável o ambiente de tal encontro, sobretudo o fato de que tal placa despertara naquele jovem casal distintas reações, identificações ou interações com os conhecimentos por ela despertados e com suas próprias histórias pessoais. Construir monumentos, marcar espaços, conservar ruínas, são processos que implicam lutas, escolhas e produzem sentidos que escapam às intenções de seus produtores. Reside aí o inusitado deste encontro com João Cândido, transformado em aposta na importância de nossos diálogos, como professoras e pesquisadoras, com os sujeitos que guardam as histórias e as memórias dos povos indígenas e negros em nossas comunidades.

Nos escritos a seguir refletiremos sobre alguns pontos centrais da relação patrimônio cultural, ensino de História, racialidade e etnicidade, temas que, por sua complexidade, são abertos e tem muitos pontos de fuga. Abordar as memórias indígenas e afro-brasileiras no ensino de História envolve esquecimentos, silêncios e gestos em um jogo de saberes e emoções. $O$ aporte teórico que nos orienta é a compreensão do conceito de cultura no plural (CERTEAU, 1995), o que significa afirmar que negamos a ideia de patrimônio como um produto cultural único e acabado. O que nos interessa, nesse processo, é buscar analisar tanto o produto cultural oferecido quanto a forma como os usuários operam o mesmo. Tais operações culturais são analisadas como movimentos cujas trajetórias não são indeterminadas, mas insuspeitáveis (CERTEAU, 2014). Embora o autor trate do domínio da pesquisa, ele aponta para a ideia de que, ao tratar de objetos da cultura, é "necessário voltar-se para a proliferação disseminada de criações anônimas e perecíveis que irrompem com vivacidade e não se capitalizam" (CERTEAU, 2014, p. 13).

As reflexões que ora apresentamos articulam as temáticas da educação das relações étnico-raciais, das histórias e culturas indígenas, africanas e afro-brasileiras, analisando os usos de espaços de memória, monumentos, arquivos, museus e memoriais. Tais espaços serão tematizados a partir da capacidade ou não de proporcionarem visibilidade e positividade para negros e indígenas, em suas múltiplas experimentações históricas e culturais. Cruzaremos nossas análises, baseadas na perspectiva do pensamento pós-colonial e decolonial latinoamericano (QUIJANO, 2005; MIGNOLO, 2003; WALSCH, 2013) com nossas experimentações de ensino, pesquisa e extensão em educação, patrimônio e relações étnico-raciais, desenvolvidas como docentes responsáveis pela formação inicial e continuada através do curso de História da Universidade Federal do Rio Grande do Sul (UFRGS).

\section{Indígenas e negros no Brasil: estranhamentos entre passado e presente a partir do pressuposto da decolonização dos saberes}

Pensar historicamente pode implicar certos estranhamentos sobre o passado e um olhar crítico sobre os usos do mesmo no presente. Na temática que ora apresentamos esses estranhamentos são fundamentais. No caso do pensamento póscolonial, gerido e pautado entre intelectuais latinoamericanos, o que se propõe é justamente estranhar a forma como ainda hoje construímos nossos conhecimentos e ações em diversos campos, pautados por um pensamento colonizador. Esse estranhamento nos leva ao passo seguinte, que é o reconhecimento de que nossos saberes e currículos são igualmente colonizados e, que, portanto, uma 
decolonização é necessária no âmbito de quem atua numa perspectiva que busca o protagonismo latino-americano.

Destacamos, a partir de Nilma Lino Gomes, nossa escrita num contexto que "exige mudança de práticas e descolonização dos currículos" (GOMES, 2012). Tal mudança, por nós experimentada, impulsiona a construção de novos olhares como pesquisadoras e professoras atuantes na formação inicial e continuada. Para a autora, tal

[...] olhar produzirá imagens desestabilizadoras, susceptíveis de desenvolver nos estudantes e nos professores a capacidade de espanto e de indignação e uma postura de inconformismo, as quais são necessárias para olhar com empenho os modelos dominados ou emergentes por meio dos quais é possível aprender um novo tipo de relacionamento entre saberes e, portanto, entre pessoas e entre grupos sociais (GOMES, 2012, p. 107).

O conceito de colonialidade do poder, desenvolvido pelo peruano Aníbal Quijano e ampliado pelo argentino Walter Mignolo, ajudanos na empreitada que é pensar o patrimônio cultural indígena e afro-brasileiro, tramado nos processos de dominação e opressão pós-colonial. É, em síntese, uma chave de leitura para compreender como a memória de tais grupos tem lugar ou nãolugar nas instituições de memória. Os estudos desses autores são um convite para pensarmos no que Mignolo (2003) chama de geopolítica do conhecimento, fazendo-nos crer que somente estudiosos posicionados em determinados lugares, culturas e línguas têm o direito ao pensamento, à filosofia, à ciência. Para esses autores, o fim da colonização não significou o fim das relações de colonialidade, que continuam pautando as relações econômicas, políticas, sociais e de produção de conhecimento. Em outros termos, não é possível pensar os triunfos da modernidade ocidental sem compreender a colonialidade do saber e do poder.

Ao argumentar sobre essa colonialidade do saber e do poder, Quijano (2005) nos coloca diante da importância da compreensão da ideia de raça como um eixo do padrão de dominação colonial europeia. Para o autor, trata-se de "uma construção mental que expressa a experiência básica da dominação colonial e que desde então permeia as dimensões mais importantes do poder mundial, incluindo sua racionalidade específica, o eurocentrismo" (QUIJANO, 2005, p. 117). Do ponto de vista histórico, a ideia de raça parece ter sido aplicada pela primeira vez aos povos originários da América, dentro do processo de dominação colonial dos séculos XV e XVI, fundamentando-se em critérios e pontos de vista nascidos das experiências europeias. A descoberta do outro está na origem da necessidade de traçar distinções. Tais diferenciações começam a se vincular nas narrativas de época e na historiografia posterior, marcadamente eurocêntricas, com atributos físicos e hábitos culturais reiteradamente destacados como inferiores, capazes de construir uma história de classificação social racializada da população mundial. Nessa perspectiva, ao contar a história do mundo, em geral e da América, em específico, o atributo cor começa a ganhar força como divisor fundamental na distinção e classificação social. A invenção da categoria cor, como indicação visível de raça, ou como seu equivalente, tem suas origens relacionadas, no caso brasileiro, às experiências de colonialismo aqui implementadas.

No Brasil que se inaugura com a colonização portuguesa, um processo de naturalização das diferenças se expressou ao longo dos anos através das desigualdades de oportunidades experimentadas por indivíduos e grupos com atributos étnico-raciais distintos. Independente das considerações biológicas, o racismo brasileiro desenvolveu-se através de práticas discriminatórias relativas à cor e, quanto mais próximo da branquitude, menor pode ser o sofrimento e a distinção preconceituosa. O que isso tem a ver com o jeito como contamos a nossa história, ou seja, com a historiografia? Para responder tal pergunta, é importante buscar as presenças e ausências de brancos, negros e índios nas narrativas historiográficas e nos manuais didáticos de história do Brasil. Muitas alternativas de resposta estão relacionadas com nosso processo de dominação colonial, mas também com a forma como nossa história foi sendo contada e reconstruída, predominantemente a partir de referenciais eurocêntricos e brancos. Talvez, por isso, nos entendamos tão pouco como americanos, mesmo estando aqui situados, cultural e geograficamente.

Ao refletirmos sobre a produção dos últimos quinhentos anos de história do Brasil, necessitamos repensar essa naturalização do referencial europeu como aquele que nos orienta para atribuir imagens de quem somos, pois essa foi a tônica do jeito como fomos construindo nossas ideias de nação brasileira. A referência centrada na 
Europa é também a forma como se organizam os currículos de História na educação superior e na educação básica, o que significa que ainda aprendemos e ensinamos mais Europa e menos América ou África, da mesma forma que permanecemos, em geral, tratando da América e da África com uma perspectiva eurocêntrica. Por outro lado, é preciso ressaltar que estamos vivendo um momento de esforço no sentido de trazer as histórias e culturas indígenas, africanas e afrobrasileiras para o cenário de nossas explicações e para nossas aulas de história.

Desde os anos 30 do século XX, o termo negro começou a ser utilizado com um significado diferenciado, pois até então ele correspondia a uma expressão vinculada a noções de vitimização e escravização. A ideia de usar o termo com positividade é relativa ao seu emprego pelos primeiros etnógrafos da cultura negra no Brasil, a exemplo de Gilberto Freyre. Negro ou afrobrasileiro tornam-se expressões utilizadas para designar as maneiras de viver dos negros e os traços de cultura popular de influência africana. Simultaneamente à positivação do uso desses termos, houve a construção do mito da democracia racial, que desconsiderava os conflitos étnicoraciais como marcadores das desiguais possibilidades de acesso aos bens públicos e de ascensão social, especialmente para descendentes de indígenas e africanos. A partir desse novo emprego do termo negro, utilizado por setores considerados da intelectualidade brasileira, surge uma controversa popularização e politização da ideia de negro, também observada através de discursos e práticas de outras organizações e movimentos sociais.

Nas últimas décadas, o mundo assiste a movimentos sociais, intelectuais e políticos pela promoção do diálogo intercultural e da igualdade racial, que tiveram um ponto de culminância na realização, em 2001, da III Conferência Mundial de Combate ao Racismo, Discriminação Racial, Xenofobia e Intolerância Correlata, em Durbin, África do Sul, cujas declarações e documentos tornaram-se referência internacional. Já naquele momento, o Estado Brasileiro assumiu publicamente o compromisso de reforçar e desenvolver ações afirmativas contra a discriminação racial também no campo da Educação.

No Brasil, o contexto inaugurado com a promulgação das Leis 10.639/03 e 11.645/08 que criaram e alteraram, consecutivamente, o artigo
26-A da Lei de Diretrizes e Bases da Educação Nacional (LDBEN), inserido no conjunto das políticas afirmativas para a promoção da igualdade racial, foi historicamente inovador ao trazer para o embate público as práticas do racismo, do preconceito e da discriminação, tradicionalmente negadas ou mantidas no plano privado.

No campo da Educação, a inovação se anunciou com força, convocando em especial, mas não somente, os professores de História a um redimensionamento de suas práticas pedagógicas, capazes de fundamentar uma educação das relações étnico-raciais balizada por valores que promovam a justiça, a cidadania, o diálogo intercultural, a ética, a paz e a igualdade racial.

Os caminhos da desigualdade étnico-racial na História do Brasil são tão intensos que se fez imperiosa a criação de movimentos para a afirmação da necessidade de construir um contexto de reparação histórica, este que nos é dado viver nos dias de hoje. É preciso destacar que muitos brasileiros, organizados em movimentos de pertencimentos étnico-raciais diversos, como os movimentos negros e indígenas, construíram esse processo histórico de reivindicações e lutas, instituinte de posições e políticas públicas recentes do país.

O racismo, a discriminação e a intolerância não são visíveis apenas na sociedade brasileira, porém aqui eles se desenvolveram com especificidades que precisam ser compreendidas do ponto de vista histórico. Nossa trajetória de composição nacional é marcada pela colonização europeia, consolidada através da imposição de força sobre os povos originários dessas terras, assim como sobre os povos africanos para cá traficados como escravos. Tratamos aqui do subjugo e da resistência experimentados por uma pluralidade de povos e origens étnicas, tanto indígenas quanto africanos, com diversos idiomas, crenças, hábitos, conhecimentos e heranças culturais singulares. Essa diversidade, porém, foi sendo negada na medida em que a experiência fundante de dominação colonial se solidificou sobre a valorização e padronização de formas de viver, pensar e agir advindas dos grupos de origem europeia que aqui se instalaram.

Ao contrário da propulsão de uma sociedade baseada na beleza da valorização das diferenças e da promoção da equidade étnico-racial, ocorreu a cristalização de olhares estigmatizantes relativos às características físicas e fenotípicas de indígenas e negros, tornados passíveis de 
identificação e discriminação por conta da cor da pele, tipo de cabelo, traços de nariz ou boca.

A mistura de ameríndios, afrodescendentes e eurodescendentes, resultante desse processo de dominação colonial, construiu, ao mesmo tempo, dois fenômenos sócio-históricos: por um lado, traçou profundos abismos no tecido social brasileiro, marcados pela distinção e desigualdade baseada em critérios étnico-raciais; de outra perspectiva, possibilitou a edificação de pontes criadas por trocas culturais singulares. Abismos e pontes gestaram-se em narrativas que oscilam entre o público e o privado, exigindo ao estudo da temática das relações étnico-raciais olhares abertos às complexidades e perplexidades da humanidade, presente em todos e em cada um de nós. Brasil?

Nesse contexto, o que é específico do

O racismo brasileiro solidificou-se historicamente através da invisibilidade experimentada nas relações informais e íntimas do cotidiano das pessoas, reproduzindo-se em gestos diários de negativação, ridicularização e estigmatização dos grupos não brancos do país. Ao mesmo tempo, é possível verificar com transparência, em levantamentos e estudos sobre a população brasileira, a sociedade racializada em que vivemos. Os dados estatísticos do censo de 2010, por exemplo, mostram traços muito visíveis de uma desigualdade racial que tem diminuído pouco nos quesitos educação e renda. Nesse levantamento, os brancos, assim como no censo de 2000, seguem recebendo salários mais altos e estudam mais que os negros; igualmente dominam o ensino superior no País e ainda há diferenças relevantes na taxa de analfabetismo entre as categorias de cor e raça. Assim, enquanto, para o total da população, a taxa de analfabetismo é de $9,6 \%$, entre os brancos esse índice cai para 5,9\%. O censo de 2010 mostrou que cerca de $70 \%$ da população brasileira tem relacionamentos amorosos com pessoas do mesmo grupo de cor ou raça. Dados desse tipo demonstram o profundo abismo que nos divide, capaz de criar oportunidades sociais de acordo com critérios baseados na etnicidade e na racialidade. Tais informações devem ser analisadas em perspectiva histórica, ou seja, podem nos levar a criar estranhamentos na forma de compreender $o$ presente quando em estreita relação com as experiências do passado. Esses estranhamentos criam novos olhares sobre os espaços de memória e a capacidade ou não de proporcionarem visibilidade e positividade para negros e indígenas. Vejamos, a seguir, alguns exemplos sobre o que nos apresentam os museus brasileiros acerca das memórias e ancestralidades indígenas, afrobrasileiras e africanas.

\section{Presenças e ausências de memórias indígenas, afro-brasileiras e africanas nos museus brasileiros}

Os museus, na qualidade de espaços privilegiados para a preservação da cultura material, reafirmaram/reafirmam uma memória nacional que expõe e valoriza objetos e ideias relacionadas ao quadro de referências culturais branca, católica e europeia. As expressões de grupos populares e historicamente marginalizados ficaram invisibilizadas no processo de invenção do projeto de nação, construído a partir do período de independência, apesar do grande contingente populacional africano e indígena presente na sociedade brasileira oitocentista. Nessa nação construída, povos e culturas foram subalternizados; saberes, memórias e histórias locais foram silenciados pela colonialidade do poder, mantida apesar do rompimento político-administrativo dos laços coloniais com Portugal.

Hoje, vivemos a emergência de outro pensamento, pós-ocidental (MIGNOLO, 2003), capaz de operar para a descolonização intelectual. Esse pensamento, segundo o autor, constrói-se a partir dos estudos de intelectuais africanos, árabes, latino-americanos, tais como Paulo Freire, Aníbal Quijano, Enrique Dussel, Darcy Ribeiro, Roberta Menchú, Rivera Cusicanqui, Rodolfo Kusch, Franz Fanon, Khatibi, entre outros, que pensaram o conhecimento na perspectiva da colonialidade do poder e da construção de outras narrativas sobre o presente e o passado desses espaços no mundo.

Nesse cenário, também os museus, como expressão de uma Nova Museologia, cada vez mais modificam suas exposições buscando apresentar uma narrativa mais diversa, plural e transgressora. O estudo de Nila Rodrigues Barbosa (2010), no Museu Histórico Abílio Barreto, de Belo Horizonte, é exemplo. No acervo, os objetos de suplício, fotografias e textos não eram relacionados ao negro, mas a "tipos populares", o que indicava o não lugar do negro no acervo museológico e a necessidade de nomear tecnicamente os objetos do acervo. Como parte desse tensionamento, a equipe do Museu organizou a exposição "Uma questão de raça: representações do negro no museu da cidade", na qual a curadoria 
expôs as omissões e equívocos em relação ao negro.

Outro exemplo diz respeito à exposição apresentada em 2013, no Museu Júlio de Castilhos/RS, sobre Aurélio Veríssimo de Bittencourt, um jornalista negro que foi chefe de gabinete de Júlio de Castilhos e Borges de Medeiros, membro da Irmandade do Rosário e da Academia Rio-Grandense de Letras. A exposição, apesar de ser uma ação pontual do Museu Júlio de Castilhos, valorizou a atuação de um negro, indo além do lugar comum de outras representações que destacam negros artistas e jogadores. Vale destacar que essa exposição tem importância, também, por ter sido criada nesse museu, que adotou uma tipologia histórica comprometida com a construção de uma memória oficial do estado. Por outro lado, a exposição coloca acento em um negro bemsucedido.

Marcelo Cunha (2006, p. 99), investigando exposições de nove museus brasileiros, constata que o discurso sobre as populações africanas e afro-brasileiras se situa no passado e que as "[...] análises na perspectiva das dinâmicas históricoculturais de luta e resistência frente às seculares agressões ocidentais estão ausentes nos discursos expográficos sobre África e sociedades da diáspora negra". Nas conclusões de sua pesquisa, o autor aponta algumas recorrências: primeiro, constata que são raras as exposições sobre africanos e afrobrasileiros, em geral aparecendo como apêndices de outras narrativas pautadas na história branca ocidental. Tal omissão expressa o entendimento da cultura africana tangenciando a brasileira "sem que seja afirmado, de forma categórica, que estamos falando de uma das bases essenciais da pretendida cultura nacional" (CUNHA, 2006, p. 240). Em segundo lugar, o autor afirma que há nas exposições uma tendência em apresentar a África cristalizada em experiências do passado, povoada por culturas tradicionais, na qual os modos de vida estariam marcados pela permanência de costumes, criando uma visão homogeneizadora acerca desse Continente destacadamente rico em pluralidades do ponto de vista sociocultural. Igualmente, suas análises indicam que "[...] não encontramos exposições que apresentem referências contemporâneos do Continente, na sua complexidade decorrente dos diversos momentos históricos, desde o período pré-colonial até a atualidade" (CUNHA, 2006, p. 241). Os museus e suas exposições, sob esse ponto de vista, são construídos majoritariamente na lógica do pensamento ocidental, descritor do continente africano como desqualificado e construtor de imagens estereotipadas perpetuadas em diferentes contextos históricos. Em terceiro lugar, para o autor, as exposições enfatizam o lugar do negro no passado colonial ou imperial da monocultura, como vítimas submetidas à violência do sistema escravista, sem capacidade de reação. Quando as marcas da resistência aparecem em tais expografias, são na forma de comportamentos individuais e aleatórios que fortalecem o imaginário da desobediência. Silencia-se sobre resistências cotidianas nas senzalas, experiências comunitárias, revoltas que ganharam as ruas ou o movimento quilombola, ainda recortado e tratado somente a partir do Quilombo de Palmares. Marcelo Nascimento Cunha refere-se ao branqueamento dos museus, com exposições que reduzem a participação do negro na sociedade brasileira ao contexto da escravização, sendo que perseguições religiosas, desigualdade social e preconceito racial não parecem interessar aos museus brasileiros. São raras as exceções. Uma delas é o Museu Afro-Brasil de São Paulo, cujo discurso procura valorizar a participação do negro em diversos setores, principalmente na arte. A sede do museu é no Pavilhão Padre Manoel da Nóbrega, dentro do movimentado Parque Ibirapuera, num prédio modernista, projetado por Oscar Niemeyer e denominado, a princípio, de Palácio das Nações, construído para as comemorações oficiais do IV Centenário da Cidade de São Paulo. O museu conserva um acervo com mais de 6 mil obras, entre pinturas, esculturas, gravuras, fotografias, documentos e peças etnológicas, de autores brasileiros e estrangeiros, produzidos a partir do século XVIII até os dias de hoje, tendo como curador e fundador $\mathrm{o}$ artista plástico baiano Emanoel Araújo. O Museu Afro-Brasil, apesar de ter sua sede em uma edificação que diretamente não possui ligação com a temática do acervo, expõe fragmentos das culturas africanas e afrobrasileiras e nos convida a refletir sobre a importância do negro na construção do Brasil em diferentes espaços e tempos.

O Museu Afro-Brasil, criado em 2004, representa um novo momento na valorização das culturas africanas e afro-brasileiras no país, embora seja importante lembrar que as iniciativas dessa natureza começaram já na década de 1980 com o tombamento da Serra da Barriga, localizada no município de União dos Palmares, inscrita no Livro do Tombo Arqueológico, Etnográfico e 
Histórico, em 1986; a criação da Fundação Cultural Palmares, em 1988; o Memorial Zumbi dos Palmares, inaugurado em 1990 para ser um centro cultural destinado a promover ações afirmativas de valorização da cultura africana e afro-brasileira e a fundação do Museu Nacional da Cultura Afro-brasileira (MUNCAB), em 2002. Nesse mesmo cenário, é importante destacar o crescimento dos museus que se dedicam a compor um acervo que valoriza diferentes etnias, entre os quais: Museu Nacional da Cultura Afro-Brasileiro em Salvador (BA), Memorial Mãe Menininha do Gantois em salvador (BA), Casa do Benin em Salvador (BA), Memorial das Baianas em Salvador (BA), Museu da Abolição em recife (PE), Museu Afro-Brasil, em São Paulo (SP), Museu AfroBrasileiro (SE), Museu do Negro (RJ), Museu 13 de Maio, em Santa Maria (RS), Museu do Percurso do Negro, em Porto Alegre (RS), Território Negros de Porto Alegre (RS), Museu Kuahí dos Povos Indígenas do Oiapoque, em Macapá (AP), Museu Indígena, em Coroa Vermelha (BA), Museu Magüta dos Índios Ticuna em Benjamin Constant (AM).

A relação de museus étnicos evidencia também o crescimento dos estudos, questionando a forma como os museus brasileiros abordavam e abordam a história indígena, africana e afrobrasileira. Ulpiano de Menezes (1994, p. 25) aponta que "a exposição museológica pressupõe [...] uma concepção da sociedade, de cultura, de dinâmica social, de tempo, de espaço, de agentes sociais e assim por diante". Exposições contam histórias, evidenciam memórias, expressam disputas, escolhas e silenciamentos. Podem também ampliar as representações sobre diferentes grupos sociais e étnico-raciais que circulam na cidade.

Ressaltamos que, assim como na historiografia brasileira mais recente, destacadamente nos estudos do período PósAbolição, os espaços de memória começam a estudar os negros e o racismo no Brasil a partir de um pressuposto e de uma necessidade de pensar o cotidiano desses homens e mulheres como sujeitos sociais, justamente pelas especificidades das relações étnico-raciais constituídas em nosso país e evidenciadas na escrita do item anterior.

Se seguimos na argumentação que, para estudar, pensar e tratar da decolonização dos espaços de memória é igualmente necessário tratar do cotidiano e dos sujeitos sociais envolvidos nas relações que ali destacamos, urge evidenciar que esses espaços sejam pensados em relação direta com os intelectuais e movimentos sociais indígenas e negros. O protagonismo desses grupos é fundamental para que se desestabilize a colonialidade do poder e do saber.

Recorrendo aos estudos de autores como Aníbal Quijano (2005), Walter Mignolo (2003) e Catherine Walsh (2013), é possível defender uma educação decolonial nos museus, mantendo em tensão a narrativa e as vozes que as exposições apresentam. Esses pesquisadores fazem parte do grupo de investigação "Modernidade/Colonialidade" formado, predominantemente, por intelectuais da América Latina, postulando que modernidade e colonialidade são as duas caras de uma mesma moeda. Para Oliveira y Candau (2013, p. 279):

[...] el colonialismo es más que una imposición política, militar, jurídica o administrativa. Bajo la forma de colonialidad llega a las raíces más profundas de un pueblo y sobrevive a pesar de la descolonización o emancipación de las colonias latinoamericanas, asiáticas y africanas, en los siglos XIX y XX. Lo que estos autores nos muestran es que a pesar de que ya acabaron los colonialismos modernos, la colonialidad sobrevive.

Através da leitura desses autores, propomos descolonizar, na perspectiva do pensamento pós-colonial e decolonial, o museu e o patrimônio da noção de cultura eurocentrada e, sobretudo, construir pedagogias que possibilitem estar, ser, sentir, existir, fazer, pensar, escutar e saber de outro modo.

O termo descolonizar relaciona-se com o conceito decolonial. Segundo Catherine Walsh, o conceito decolonial relaciona-se, na literatura, a outros, como: descolonialidade, descolonial, como também decolonialidade e decolonial. Para a autora, suprimir o "s" é uma opção. Vejamos sua argumentação, no sentido de que o termo decolonial:

[...] pretende marcar una distinción con el significado en castellano del "des" y lo que puede ser entendido como un simple desarmar, deshacer o revertir de lo colonial. Es decir, a pasar de un momento colonial a un no colonial, como que fuera posible que sus patrones $y$ huellas desistan en existir. Con este juego lingüístico, intento poner en evidencia que no existe un estado nulo de la colonialidad, sino posturas, posicionamientos, horizontes $y$ 
proyectos de resistir, transgredir, intervenir, insurgir, crear e incidir. Lo decolonial denota, entonces, un camino de lucha continuo en el cual se puede identificar, visibilizar y alentar "lugares" de exterioridad y construcciones alter-(n)ativas (WALSH, 2013, p. 24-25).

Reconhecemos, em conexão com Walsh, que nossos saberes e nossos fazeres estão permeados pelo desejo de romper, transgredir e resistir a toda forma de persistência dos projetos colonizadores eurocentrados.

Assim, questionamo-nos sobre o que os museus ensinam das histórias e das culturas indígenas, africanas e afro-brasileiras, atentando para a conexão dos objetos das exposições com as histórias de vidas dos sujeitos que produziram tais objetos. Como objetos, palavras e imagens podem produzir argumentos que tecem histórias de vidas? Uma exposição é, também, um diálogo entre diferentes grupos: os que usaram os objetos, os que criaram a exposição e os que a visitam. Reside aí o compromisso dos museus com uma educação que transite das narrativas hegemônicas para as histórias vivas que reivindicam a presença de direitos à memória e ao reconhecimento. Exemplo interessante é o Memorial Mãe Menininha do Gantois, criado em 1992 em homenagem a uma importante mãe-de-santo do Brasil. O Memorial foi construído no mesmo local onde ocorriam as práticas culturais por ele abordadas e rememoradas, tornando-se evocador de memórias e possibilitando o encontro entre o vivido e o narrado.

Outro aspecto interessante do Memorial Mãe Menininha do Gantois é seu caráter biográfico, com ênfase mais no sujeito do que nos objetos. Se, para Marcelo Nascimento Cunha (2006, p. 105), "[...] homens e mulheres das comunidades afrobrasileiras são lembrados reduzidos ao papel de personagens, ou melhor, transformados em arquétipos como a baiana de acarajé, a mãe-desanto, o capoeira, normalmente, apresentados de forma anônima, sem vínculos ou trajetória pessoal", esse Memorial busca justamente o caminho inverso. Ao contar a história de uma liderança e de uma "casa de santo", o Memorial rompe essa lógica, igualmente segue na contramão de outros espaços de memória, na medida em que sua ênfase não está centrada na condição de escravizada de sua personagem protagonista. Para Marcelo Nascimento Cunha (2006), insistir nessa representação centrada na escravização e vitimização é limitar a reflexão à criminalização da resistência ou destacar a passividade dos sujeitos escravizados, sendo necessário dar visibilidade nas exposições para os movimentos de rebelião, já que o estudo do passado está, necessariamente, vinculado às demandas do tempo presente.

Articular ideias em torno dessas relações entre museus e ensino de História implica em reconhecer as instituições museais como lugares educativos nos quais são produzidas distintas representações. Lugares que dão a ver as formas segundo as quais os sujeitos de um grupo social se relacionam com o tempo; onde a visão é desnaturalizada e os regimes visuais de cada época podem ser compreendidos. Convictas desse pressuposto propomos aos alunos do Curso de Licenciatura em História da UFRGS, por exemplo, estágios docentes em museus, arquivos, memoriais, bibliotecas e outros projetos que tematizem a memória e a história, de forma a instigar o professor em formação a ampliar os espaços de ensinar-aprender História. A disciplina de Estágio de Docência em História III - Educação Patrimonial explora arquivos, memoriais, centros culturais, museus, acervos particulares com acesso permitido, exposições permanentes ou temporárias, bibliotecas históricas de visitação livre, prédios históricos abertos ao público, etc. Também discute questões de ordem teórica, apoiada nas noções de memória, de ensino de História e de patrimônio cultural. A carga horária dessa disciplina está distribuída em três momentos: atuação nas instituições culturais, aulas presenciais na Universidade e orientações individuais ou em grupo. Nos espaços de atuação, o acadêmico realiza observações, monitoria e docência em História, acompanhando as atividades cotidianas das instituições culturais, em especial as ações educativas, quais seja, acompanhar o mediador nas visitas guiadas, participar das reuniões de estudos organizadas pela instituição, propor atividades com o acervo e efetivar tais ações com alunos da Educação Básica. Ressaltamos que nossa atuação está fundamentada na ideia de que o patrimônio cultural é um desses temas potentes para provocar transgressões pedagógicas. Vejamos a seguir um breve relato de nossas ações de ensino e de extensão, no campo da formação inicial e continuada de professores de História, focando a experiência em parceria com o Projeto Territórios Negros: afro-brasileiros em Porto Alegre.

\footnotetext{
Experimentações com as territorialidades negras em Porto Alegre: o Projeto Territórios Negros em intersecção com o ensino e a
} 


\section{extensão universitária}

O Projeto Territórios Negros: afrobrasileiros em Porto Alegre existe desde 2009, com funcionamento regular desde 2011, e se constitui em espaço de estágio curricular do Curso de História e atualmente conta com ações extensionistas universitárias vinculadas às temáticas correlatas à Lei 10.639/03 e à educação das relações étnico-raciais. Tal Projeto é por nós compreendido como propulsor de uma metodologia própria, uma pedagogia transgressora, de acordo com o pressuposto da decolonização dos currículos, saberes e poderes. Consiste na realização de um percurso de ônibus que percorre pontos específicos da cidade, passando por regiões historicamente reconhecidas como territórios de moradias, trabalhos, lutas, sociabilidades e religiosidades vinculadas à negritude, tais como: Largo da Forca (Praça General Sampaio), Pelourinho (Igreja das Dores), Mercado Público de Porto Alegre, Campo da Redenção (Parque Farroupilha), Colônia Africana (Bairro Rio Branco), Ilhota (imediações da Av. Érico Veríssimo), Areal da Baronesa (Quilombo da Travessa Luis Garanha), Largo Zumbi dos Palmares.

Segundo Francieli Renata Ruppenthal (2015), o embrião do Projeto surgiu, conforme afirmam seus idealizadores, a partir da aplicação de uma oficina, promovida pela assessoria pedagógica de relações étnico-raciais da Secretaria Municipal de Educação de Porto Alegre (SMED), em agosto de 2008. Resultante de parcerias estabelecidas, inicialmente, entre SMED, Companhia de Processamento de Dados do Município (PROCEMPA), Secretaria Adjunta do Povo Negro e a Companhia Carris Porto Alegrense, empresa pública municipal de transporte coletivo, hoje é mantida efetivamente por três profissionais da empresa Carris que se aventuram na árdua tarefa de manter a memória afro-brasileira, ativada a partir da denúncia de sua invisibilidade e esquecimento no espaço público de Porto Alegre.

$\mathrm{O}$ crescimento da realização do percurso, atendendo mais de 30 mil participantes, entre alunos, professores e público em geral, motivou os coordenadores a buscarem, na Universidade Federal do Rio Grande do Sul, outra instituição que ajudasse a qualificar e ampliar as ações do Projeto. Em nossas ações extensionistas e de ensino, através da realização de cursos de formação e de estágios docentes no Projeto
Territórios Negros, temos buscado criar parcerias para que o mesmo ganhe força políticopedagógica, ampliando-se como experiência histórica e cultural fundamental de nossa cidade. Como profissionais da Universidade Pública, temos limites e possibilidades em nosso campo de atuação e no cumprimento de um papel específico junto à sociedade, atinente ao exercício indissociável do ensino, da pesquisa e da extensão. Nesse sentido, nos articulamos em parcerias para construir ações que caminhem na perspectiva da formação inicial e continuada dentro da temática e da metodologia do Projeto. Compreendemos que a UFRGS tem uma trajetória de pesquisas sobre as temáticas e as comunidades envolvidas no Projeto e que é sua função social compartilhar esses estudos e colocá-los em interação com os sujeitos que fazem hoje a experimentação do percurso dos territórios negros em Porto Alegre.

A partir dos pressupostos evidenciados acima, em relação ao nosso papel como formadoras no interior de uma Instituição Pública de Educação Superior, assumimos a coordenação de um coletivo de trabalho em torno do Projeto, contando com um grupo competente e comprometido, formado por técnicos do Departamento de Educação e Desenvolvimento Social, estudantes das pós-graduações em Antropologia, Geografia e História, assim como professores ou assessores da SMED e da Secretaria Municipal de Cultura, através do Museu de História de Porto Alegre.

Essa forte parceria tornou possível a realização do Curso de Extensão Territórios Negros: patrimônios afro-brasileiros em Porto Alegre, em 2015. O curso foi desenvolvido através do Laboratório de Ensino de História e Educação (LHISTE), institucionalizado como Programa de Extensão, originando-se de uma demanda trazida de fora da universidade, pelos sujeitos e grupos envolvidos com o Projeto, com o objetivo de fortalecer o mesmo. A concretização da articulação dessas parcerias em torno dessa iniciativa pioneira, que é o Projeto Territórios Negros, levou-nos a atuar em duas grandes ações: a formação contínua dos professores que realizam o percurso, por um lado e, por outro viés, a produção de material didático de apoio, tanto para os trabalhos realizados no ônibus quanto para as atividades desenvolvidas na escola, antes ou depois da realização do percurso.

Faremos, inicialmente, uma breve descrição do curso de formação. Tal experiência 
contemplou em sua consecução metodológica a criação de ações educativas com percursos próprios e inéditos, por parte dos extensionistas, mapeando as marcas de pertencimento negro no entorno das comunidades escolares de atuação dos mesmos. Com 40 (quarenta) vagas disponíveis, totalmente gratuito, foi aberto para professores, licenciandos e pessoas oriundas de movimentos sociais. Realizou-se de forma presencial e com atividades a distância (plataforma moodle) simultaneamente, concluindo-se com a construção de materiais pedagógicos a partir da experiência dos cursistas. A ação promoveu o debate em torno da questão das territorialidades negras em toda a cidade de Porto Alegre e, assim, possibilitou aos extensionistas que refletissem em suas comunidades sobre esses espaços, posteriormente criando mapas e fôlderes com percursos dos territórios negros nas suas comunidades. Esses percursos foram criados em oficina de mapeamento dos territórios selecionados nas comunidades dos educadores. Em cada um dos mapas foram apontados os locais que constituem territorialidades negras e adicionadas breves descrições com suas respectivas histórias. Temas como culturas e histórias afro-brasileiras em Porto Alegre, territórios e territorialidades negras, educação das relações étnico-raciais, pedagogia griô, entre outros, foram abordados ao longo do processo de formação, cotejado pelo desafio final de construção de percursos nas comunidades escolares. Os encontros presenciais foram realizados na Universidade e em espaços de memória como o Mocambo - Associação Comunitária Amigos e Moradores do Bairro Cidade Baixa e Arredores, organização voltada à preservação da cultura afro-gaúcha, lugar onde fizemos uma roda com alguns griôs.

Para nós, reconhecer os espaços públicos e privados frequentados, apropriados e constituídos pela população negra da capital ao longo de sua história, é função educativa e desafio da formação inicial e continuada dos professores de História. Para conhecê-los, é preciso estudá-los e esse estudo se faz em diálogo com os intelectuais que vivem e estudam em nosso entorno, igualmente com os sujeitos sociais que guardam as memórias desses grupos que pouco conhecemos.

No processo de desenvolvimento dessas parcerias, compreendemos a necessidade de aprofundarmos conceitos correlatos à História em diálogo com outras áreas como Antropologia e Geografia. Retomando, por exemplo, o conceito de territórios, central no Projeto em questão, referenciamos que, nesse percurso, o que se propõe é, também, ocupar o centro da cidade, retomar e encontrar-se com as memórias negras que vão além dos registros oficiais e do patrimônio edificado de Porto Alegre, ainda centrado na valorização do modelo arquitetônico europeu. No percurso, o mediador enfatiza a presença das populações negras na cidade, sugerindo uma "reterritorialização" do centro para experienciar a cidade com múltiplos olhares. Lembramos aqui a noção de territorialidade negra, discutida por Iosvaldyr Carvalho Bittencourt (2010). Para o autor, as populações negras teriam vivido uma dupla desterritorialização: na África, ao serem retirados de sua terra e, na América, ao serem privados de liberdade. Iosvaldyr (2010) indica, no início do século $\mathrm{XX}$, o processo de periferização das populações negras e brancas empobrecidas em Porto Alegre, pressionadas a se deslocarem do centro para locais mais afastados da cidade.

Trabalhamos com o conceito de territorialização a partir da ideia de usos dos espaços, ou seja, o sujeito pode se desterritorializar sem necessariamente ter saído do lugar e viceversa. Assim, a desterritorialização não é apenas a remoção ou o deslocamento das populações, é igualmente a desativação dos processos de vínculo dos sujeitos com os espaços. Além das migrações e deslocamentos forçados, como os citados acima, podem ser exemplos disso a proibição de práticas religiosas, a mudança de nomes de lugares, entre outros. No caso de Porto Alegre, por exemplo, o lugar chamado, a partir do século XIX, de Colônia Africana, pouco a pouco foi apagado da história da cidade. Tratava-se de um espaço habitado por negros, no período da abolição do pós-abolição, mas que igualmente acolhia imigrantes desembarcados em Porto Alegre e que não seguiam para as colônias alemãs ou italianas. Tal região da cidade foi retratada na literatura e em estudos diversos como local de marginais e marginalizados. Sabemos que os moradores negros da Colônia Africana foram "removidos" da região pela ação dos poderes públicos e da especulação imobiliária (KERSTING, 1998). Entretanto, estudos mais recentes (ROSA, 2014) indicam que foi também a atitude de alguns moradores da Colônia Africana, notadamente imigrantes brancos, motivo de aversão ao local e aos seus moradores negros e contributo para sua desterritorialização. Hoje, o espaço urbano em que existia a Colônia Africana, em termos de especulação imobiliária, é 
um dos locais mais caros da cidade e congrega bairros como Rio Branco, Bom Fim e Mont'Serrat. Tal espaço faz parte do percurso realizado pelo Projeto Territórios Negros: afro-brasileiros em Porto Alegre.

Quando tratamos dos territórios negros não estamos apenas tratando dos espaços de exclusão, mas dos agenciamentos e das estratégias dos sujeitos em seus cotidianos para uso dos espaços da cidade. O protagonismo dos sujeitos, nessa perspectiva, é fundamental, pois a territorialidade é justamente a multiplicidade de usos de um mesmo território, entendido como lócus de disputas entre os sujeitos (SANTOS, 2009). É justamente esse protagonismo que se busca evidenciar no percurso dessa ação educativa e patrimonial do Projeto Territórios Negros, quando se destacam os lugares e espaços de memórias praticados pelos negros, como as territorialidades quilombolas, carnavalescas, entre outras.

Entre as reflexões construídas ao longo dessa ação de extensão, destacamos aqui alguns excertos recolhidos dos fóruns virtuais constituídos ao longo do processo de consecução do curso. Eles expressam as reflexões compartilhadas acerca das experimentações metodológicas propostas, como registros de trocas de saberes dos professores em percursos de aprendizagens junto às comunidades escolares, suas territorialidades negras e seus patrimônios culturais. Vejamos:

Se fosse possível, cada Griô deveria ser tombado como Patrimônio Histórico da Humanidade, visto que, eles são alicerces fundamentais nas narrativas de culturas que não são retratadas pela cultura letrada. A oralidade contrasta com o que há de mais moderno que temos, a Era Digital. Os povos/etnias que não possuem a sua ancestralidade registrada ou documentada utilizam da memória e da oralidade para transmitir às gerações futuras o seu contexto histórico e manterem viva a sua própria história. Assim, temos nas culturas negras africanas e nas culturas indígenas, a religiosidade, a musicalidade, a dança, a ritualística, presentes até os dias de hoje. Se não fossem os Griôs responsáveis pela transmissão de todos esses conhecimentos, certamente boa parcela dessas culturas já haveria desaparecido. Eis que cabe a nós, educadores, desenvolvermos práticas de ensino que não utilizem somente o conteúdo programado, mas sim, a interação com a cultura de nossos alunos mediantes suas experiências e anseios sociais. Não podemos ficar atrelados ao livro didático [...] que tenta diminuir a importância daqueles que não possuem a matriz europeia. [...] resposta para o profissional que buscar fazer a diferença está no seu cotidiano escolar, na comunidade trabalhada, com o seu grupo educacional envolvido. Essa resposta se constrói constantemente [...]. (Relato 1, cursista e professora da rede pública estadual, Porto Alegre. Fórum virtual na plataforma moodle/UFRGS do Curso de Extensão Territórios Negros: patrimônios afrobrasileiros em Porto Alegre, 2015).

[...] Meus sentimentos são de felicidade $e$ angústia. Felicidade pela oportunidade, ainda que tardia, de estar aprendendo, de me sentir viva com estes "novos" conhecimentos e ter a certeza de que ainda é possível fazer a diferença. Por outro lado, sinto uma enorme angústia ao perceber minha falta de conhecimento em temas que agora percebo como básicos e essenciais. Há mais de 20 anos atuo em escolas onde maioria dos alunos são negros. A história destes alunos sempre foi tratada com superficialidade. Nos três últimos anos já fazia uma tentativa de qualificar o meu trabalho, o que inclusive me levou a procurar o curso, mas percebo que deixei muito a desejar por falta de conhecimento. Desconhecia a força e riqueza desta história. Muito transitei na frente do MOCAMBO que visitamos e não sabia de sua existência assim como de seu significado. Griôs, outro termo desconhecido e mais o seu papel e perfil [...] (Relato 2, cursista e professora da rede pública estadual, Porto Alegre. Fórum virtual na plataforma moodle/UFRGS do Curso de Extensão Territórios Negros: patrimônios afrobrasileiros em Porto Alegre, 2015).

[...] muitos destes aspectos negados da cultura africana estão expostos por seus descendentes dentro de nossas comunidades escolares, o que nos cabe é ter esta percepção atenta. No cotidiano e na crítica podemos notar comportamentos e ações que ainda nos remetem ao momento interior da negação comportamental e territorial, e propiciam construção de um novo território simbólico. [...] os mapas não trataram de revelar esta luta interna, trataram de pormenorizar as populações a uma nação homogênea com a mesma língua, que foi resumida a números demográficos. Tratemos de fazer nossos núcleos locais múltiplos para múltiplas visões [...] (Relato 3, cursista e professora da rede pública estadual, Porto Alegre. Fórum virtual

Horizontes, v. 35, n. 1, p. 19-34, jan./abr. 2017 
na plataforma moodle/UFRGS do Curso de Extensão Territórios Negros: patrimônios afrobrasileiros em Porto Alegre, 2015).

[...] Os conflitos expostos no texto da Isabel nos remetem a nossa própria história expondo as mesmas estratégias usadas pelos portugueses na África e pelos exploradores do mercado imobiliário em Porto Alegre. A pressão pelo espaço privilegiado, a redução da cultura local até que ela seja considerada 'errada', a imposição de uma nova estética foram as mesmas formas de dominação utilizadas para empurrar para as áreas periféricas as populações negras que habitavam o entorno da área central da cidade. Exemplo de resistência pela sua cultura e identificação histórica, o Areal da Baronesa e o espaço Mocambo, mostram que a resistência aconteceu (e acontece) ainda hoje na nossa cidade. A preservação da história local, o mapeamento afetivo da região constitui-se na estratégia mais forte de manutenção do sentimento de pertencimento da comunidade e sua efetiva resistência a uma padronização e massificação da cultura [...] (Relato 4, cursista e professora da rede pública estadual, Porto Alegre. Fórum virtual na plataforma moodle/UFRGS do Curso de Extensão Territórios Negros: patrimônios afrobrasileiros em Porto Alegre, 2015).

Esses breves fragmentos merecem análise e compreensão de nossa parte, porém o objetivo de trazê-los na escrita que ora produzimos não é outro senão evidenciar as possibilidades criadas num processo de formação continuada, as problematizações e desestabilizações construídas em momentos de trocas, capazes de criar movimentos de resistência e transgressão do ponto de vista curricular. Tais movimentos conectam-se com o pensamento decolonial que ora nos fundamenta.

Pensemos, a partir de agora, nos estágios de docência em espaços de memória pouco convencionais, a partir do caso específico do Projeto Territórios Negros em Porto Alegre. Tal Projeto constitui-se como espaço de estágio de docência do Curso de História desde 2013-2. Portanto, durante cinco semestres (até 2015), 14 acadêmicos realizaram $10 \mathrm{~h}$ de observação e $30 \mathrm{~h}$ de docência percorrendo o centro de Porto Alegre com alunos da Educação Básica, fazendo aula fora do espaço convencional da aula. No final do semestre cada estagiário elabora um artigo que se organiza a partir de uma questão-problema construída durante sua vivência no espaço de memória. Orientar essa escrita nos possibilita acompanhar o processo de reflexão que cada um constrói durante o estágio, percebendo a relevância da inserção do professor em formação em espaços de memórias. Entre as aprendizagens da docência, indicadas pelos estagiários do Projeto Territórios Negros, destacamos algumas na forma de excertos retirados de suas escritas. Vejamos:

[...] preciso abrir mão de velhas certezas sobre o tempo, refletir sobre seu desenvolvimento anterior ao discurso histórico nas experiências culturais diversas de tempo, pensar as relações de poder que o modelo de tempo moderno encenou como a colonialidade do tempo subalterno e abrir mão de velhos binarismos que estiveram presentes no discurso histórico. O tempo da diáspora poderá trabalhar a experiência museal nas ações educativas em situações entre lugares, como no Territórios Negros, para posicionar estrategicamente continuidades para as futuras rupturas (GONZAGA, 2015, p.69-70).

[...] o processo de aproximação com a cultura de matriz africana, seja ela através da capoeira, seja através da religião, possibilitou através de suas próprias vivências prévias ou da representação, entendida como trazer a presença algo que estava ausente, positivar a cultura africana em suas manifestações e assim gerar um processo de identificação $e$ pertencimento a esta matriz cultural (DIEHL, Isadora Lunardi, 2014).

Nos diversos momentos do percurso realizado pelo projeto Territórios Negros em que foram abordadas, de forma direita ou indireta, as identidades religiosas de matriz africana, foi possivel identificar três tipos de comportamento recorrentes: para alguns alunos, este momento revelou uma certa ânsia por se fazer ouvir, a partir de uma fala que procurava, principalmente, desvincular sua religião às associações com o 'demônio' 'diabo', um mal a ser combatido; outros, mesmo instigados por seus professores a trazerem suas contribuições enquanto praticantes destas religiões, silenciaram, o que se pode compreender como um mecanismo de defesa; houve ainda aqueles preocupados em apontar, ou mesmo "acusar", o pertencimento de outrem a uma religião de matriz africana, frente a qual declararam sentir "medo (VALADA, Luana Veeck. 2014).

Olhar diferente para a cidade, pois os 
territórios negros são colocados de forma secundária na narrativa histórica de Porto Alegre, sendo a povoação açoriana o discurso oficial apresentado (MEDEIROS, Tanise Baptista de, 2013).

Abrir mão de velhas certezas é, certamente, um belo exercício no fazer-se professor de História. Suspeitar que, talvez, os conteúdos de sempre e as abordagens que privilegiam a matriz teórica embasada em autores europeus necessitem ser ampliadas para que possamos perceber as memórias e histórias invisibilizadas nos currículos e no "lugar oficial de memória" (museus), acreditando que esse movimento é fecundo na formação do professor de História. Dialogar com crianças e jovens sobre memórias indígenas, africanas e afro-brasileiras, problematizar conceitos como preconceito, resistência, estranhamento, pertencimento, patrimônio cultural, seguindo os ensinamentos de Quijano (2005), contribui para que possamos, a cada dia, aprender como o poder e o saber outorgaram à diversidade $o$ caráter de problema, impondo a ideia de que não só a pele fosse branca, mas também as mentalidades.

É profícuo para o professor em formação deparar-se com perguntas, tal como aquela de uma criança que, ao sair do Mercado Público (no centro de Porto Alegre), indaga a estagiária sobre a Tradição do Bará do Mercado: "professora, porque essa história nunca é contada? As pessoas passam todos os dias por ali e nem sabem o que significa aquilo no chão" (Escrita de estágio de Caroline Silva Uezu). Uma indagação como essa nos faz refletir sobre as intensas e positivas possibilidades que a experiência da visita ao Mercado Público e ao mosaico ali esculpido no chão, em granito vermelho e amarelo, monumentando e registrando nosso patrimônio imaterial e religioso, o Bará do Mercado. Em termos de ação educativa trata-se de um exemplo de transgressão, ao trazer a presença de algo que estava ausente e invisibilizado e, assim, questionar o caráter monocultural e o etnocêntrico do currículo escolar. Supõe a possibilidade de perguntar sobre as escolhas curriculares e desestabilizar a pretensa neutralidade dos conhecimentos e práticas educativas.

No exercício da docência, o estagiário, ao abordar a história africana e afro-brasileira, pode se colocar diante dos desafios da educação das relações étnico-raciais, pois identifica atitudes de preconceito racial e busca problematizar, desnaturalizar e questionar estereótipos e preconceitos individuais e sociais. Vejamos mais um excerto: [...] no início da viagem, um aluno com apenas 10 anos, apontou para o meu cabelo e afirmou que ele era "ruim", feito de "teia de aranha" (GOMES, Matheus, 2015).

Nessa experiência específica, o estagiário foi vítima das representações que circulam na sociedade e fazem com que as crianças e jovens não tenham orgulho de seu pertencimento. $\mathrm{Na}$ sequência, o estagiário conta que:

[...] em turmas onde nitidamente tínhamos uma maioria negra, menos da metade dos alunos se manifestava quando perguntávamos quem se identificava como tal. A esmagadora maioria dos estudantes negros não sabiam o significado de nenhum dos locais onde ocorreu a história de seus antepassados, ou seja, um 'vazio histórico' precisa ser coberto na consciência pela educação. A reprodução de piadas que reforçavam a construção do estereótipo animalesco do negro construído desde o século XVI era frequente e inclusive me encontrou como vítima em uma ocasião (GOMES, Matheus, 2015).

Mergulhar nesse universo de discriminações e preconceitos, em alguns casos sutil e naturalizado; problematizar representações construídas historicamente e oportunizar encontros com diferentes histórias e memórias é condição para a docência nas escolas de hoje: sem tais elementos é quase impossível seguir caminhando em direção à escola multicultural, capaz de experimentar a equidade nas relações étnicoraciais.

\section{Considerações finais}

A articulação entre as temáticas da educação, do patrimônio e das relações étnicoraciais nos instigou nessa escrita, dentro da perspectiva do pensamento decolonial, uma vez que estamos muito sensibilizadas e provocadas pelas experiências de ensino, pesquisa e extensão que experimentamos a partir das parcerias estabelecidas com o Projeto Territórios Negros em Porto Alegre.

Tais experimentações nos colocam diante de um campo de possibilidades em que o inusitado volta a operar em nossas reflexões. Retornamos ao 
episódio narrado no início desta escrita para destacar novamente a importância da relação com o patrimônio, estabelecida pelos sujeitos em interação, nas múltiplas formas de usos de um mesmo território. Um patrimônio é escolhido e exposto para ser visualizado, ou não, conforme as demandas dos grupos sociais e das relações de saberes e poderes entre eles estabelecida. $\mathrm{O}$ inusitado, para nós, está relativo ao olhar atento para aqueles que protagonizaram e protagonizam territorialidades marcadas pelas ancestralidades locais, especialmente indígenas e afro-brasileiras.

Tratar da decolonização dos espaços de memória, como intentamos fazer na escrita que ora encerramos, requer o direcionamento de nossos saberes e sensibilidades para a vida cotidiana e para os sujeitos sociais envolvidos nas relações ou nos fatos que decidimos destacar. Voltamos a dizer que, recorrendo aos estudos de autores como Aníbal Quijano (2005), Walter Mignolo (2003) e Catherine Walsh (2013), defendemos uma educação decolonial nos museus, mantendo em tensão a narrativa e as vozes que as exposições apresentam. Que sujeitos são os protagonistas de nossas escolhas? Quem escolhe conosco? Tais perguntas evidenciam nossa posição de que os espaços de memória devem ser pensados em relação direta com as comunidades, os intelectuais e os grupos sociais organizados, particularmente no caso das presentes reflexões, indígenas e negros. O protagonismo desses grupos é fundamental para que se desestabilize a colonialidade do poder e do saber, uma vez que o conceito de raça é um conceito central nos estudos de colonialidade que nos inspiram. Essa mesma afirmação, relativa ao protagonismo das comunidades locais, é válido para os espaços educativos escolares.

O Projeto Territórios Negros, foco de nossas práticas educativas em análise, ao destacar lugares e espaços de memórias praticados pelos afro-brasileiros em nossa cidade, e as ações de ensino e extensão a ele correlatas, contribuem na construção de outras relações com a cidade e seu patrimônio cultural. Estamos num contexto de continuidades das lutas por reconhecimento de uma pluralidade sociocultural que positive as etnias de ancestralidades não europeias e suas memórias em nosso país. Reiteramos que, construir monumentos, conservar ou destruir espaços, registrar bens materiais e imateriais, são processos que implicam escolhas e produzem sentidos que escapam às intenções de seus propositores, mas que dificilmente estão isentos de posturas em relação aos saberes e aos poderes estabelecidos como hegemônicos.

Ressaltamos que a potencialidade de um trabalho com objetos ou espaços de memória, transformados em documentos ou monumentos, consiste em criar situações nas quais a curiosidade, a problematização e o encantamento dos sujeitos sejam o mote para a construção de conhecimentos e não o objetivo final de uma experimentação educativa no campo do patrimônio. O patrimônio, nessa perspectiva, deixa de ser compreendido como um produto cultural único e acabado e passa a ser perseguido através da forma como os usuários o operam.

\section{Notas}

1 I Episódio vivido e narrado por Carla Beatriz Meinerz, dezembro de 2015.

\section{Referências}

BARBOSA, N.R. O não-lugar do negro no acervo museológico: problemas e perspectivas. In: GUIMARÃES, Manoel Luiz Salgado; RAMOS, Francisco Régis Lopes (Org.). Futuro do retérito: escrita da história e história do museu. Fortaleza: Instituto Frei Tito de Alencar, 2010. p. 276- 293.

BITTENCOURT, I.C. Os percursos do negro em Porto Alegre: territorialidade negra urbana. In: VILASBOAS, Ilma Silva; BITTENCOURT, Iosvaldyr Carvalho; SOUZA, Vinícius Vieira de. Museu de Percurso do Negro em Porto Alegre. Porto Alegre: Ed. Porto Alegre, 2010, p. 9-74.

CERTEAU, M. A Cultura no Plural. São Paulo: Ed. Papirus, 1995. ___ A Invenção do Cotidiano: artes de fazer. Petrópolis, RJ: Ed. Vozes, 2014.

CUNHA, M. N.B. Teatro de memórias, palco de esquecimentos: culturas africanas e das diásporas negras em exposições. Tese apresentada no Programa de Pós-Graduação PUC/SP, 2006.

DIEHL, I. L. Processos de identificação alunoação patrimonial: uma experiência a partir dos territórios negros de Porto Alegre. Artigo apresentado para conclusão da disciplina de Estágio de Docência em História III - educação 
Patrimonial do Curso de História da UFRGS, 2014.

GOMES, M. A educação patrimonial como arena da disputa pela consciência antirracista. Artigo apresentado para conclusão da disciplina de Estágio de Docência em História III - educação Patrimonial do Curso de História da UFRGS, 2015.

GONZAGA, G. Territórios negros, patrimônio, diáspora e tempo. História e Diversidade, Cáceres, v. 7, n. 2, p. 54-72, 2015.

KERSTING, E.H.O. Negros e a modernidade urbana em Porto Alegre: a Colônia Africana (1890-1920). Dissertação de Mestrado. PPGH/UFRGS. Porto Alegre, 1998.

MEDEIROS, T. B. Territórios em disputa: a (in)visibilidade dos Territórios Negros na cidade de Porto Alegre. Artigo apresentado para conclusão da disciplina de Estágio de Docência em História III - educação Patrimonial do Curso de História da UFRGS, 2013.

MENESES, U.T.B. Do teatro da memória ao laboratório da História: a exposição museológica e o conhecimento histórico. Anais do Museu Paulista. São Paulo. N. Ser. v. 2, p. 9-42, jan./dez. 1994.

MIGNOLO, W. Histórias locais/projetos globais: colonialidade, saberes subalternos e pensamento liminar. Belo Horizonte:Editora UFMG,2003.505 p.

OLIVEIRA, L.F.; CANDAU, V. M.F. Pedagogía decolonial y educación anti-racista e intercultural en Brasil. In: WALSH, Catherine. Pedagógias Decoloniales: Prácticas insurgentes de resistir, (re) existir y (re) vivir. Tomo I. Serie Pensamiento Decolonial. Quito, Ecuador, noviembre 2013. p. 275-303.

QUIJANO, A. Colonialidade do poder,
Eurocentrismo e América Latina. In: $A$ colonialidade do saber: eurocentrismo e ciências sociais. Perspectivas latino-americanas. CLACSO, Consejo Latinoamericano de Ciencias Sociales, 2005.

Fórum virtual na plataforma moodle/UFRGS do Curso de Extensão Territórios Negros: patrimônios afro-brasileiros em Porto Alegre, 2015. Relatos 1, 2, 3 e 4, cursistas e professores da rede pública estadual, Porto Alegre.

ROSA, M. V.F. A colônia dos africanos na cidade dos imigrantes: cor, nacionalidade e disputas pela moradia em um bairro de Porto Alegre durante o pós-abolição. In: GOMES, Flávio; DOMINGUES, Petrônio (Org.). Políticas da Raça: Experiências e legados da abolição e da pós-emancipação no Brasil. São Paulo: Selo Negro Edições, 2014. p. 263-278.

RUPPENTHAL, F. R. Um percurso possivel: uma etnografia do projeto Territórios Negros em Porto Alegre/RS no âmbito da Lei Federal 10.639/03. Dissertação de Mestrado, PPGAS-UFRGS, Porto Alegre, 2015.

SANTOS, R. E. (Org.). Diversidade, espaço e relações étnico-raciais: o negro na geografia do Brasil. $2^{\mathrm{a}}$ edição. Belo Horizonte: Editora Gutenberg, 2009.

WALSH, C. Introducción. Lo pedagógico y lo decolonial: Entretejiendo caminhos. In: WALSH, C. Pedagógias Decoloniales: Prácticas insurgentes de resistir, (re) existir y (re) vivir. Tomo I. Serie Pensamiento Decolonial. Quito, Ecuador, noviembre 2013. p. 23-68.

VALADA, L. V. As religiões de matriz africana e ensino de história: as falas e os silenciamentos. Artigo apresentado para conclusão da disciplina de Estágio de Docência em História III - educação Patrimonial do Curso de História da UFRGS, 2014.

\section{Sobre as autoras}

Carmem Zeli de Vargas Gil é Professora da Faculdade de Educação e do Mestrado Profissional em Ensino de História da Universidade Federal do Rio Grande do Sul. Possui doutorado e mestrado em Educação pela Universidade Federal do Rio Grande do Sul. Realizou estágio pós-doutoral na UBA/Argentina. Possui 
graduação em História pela Faculdade Cenecista de Osório.

Carla Beatriz Meinerz é Professora adjunta do Departamento de Ensino e Currículo da Faculdade de Educação da Universidade Federal do Rio Grande do Sul. Possui mestrado e doutorado em Educação pela Universidade Federal do Rio Grande do Sul, graduou-se em História na mesma Universidade.

Recebido em dezembro de 2016.

Aprovado em março de 2016. 